Dr Vladimir Vujičić,

dipl. inž.

\section{KONZERVACIJA TEHNIČKIH SISTEMA POSTUPKOM ODVLAŽIVANJA ATMOSFERE}

UDC: $620.197: 697.93$

Rezime:

Savremeni postupak konzervacije sastoji se u hermetizaciji opreme $i$ održavanju vlažnosti hermetizovanog prostora ispod vrednosti pri kojoj ne dolazi do korozije. Odvlaživanje atmosfere može se provesti statičkim i dinamičkim postupkom.

Ključne reči: konzervacija, korozija, relativna vlažnost, hermetizacija, odvlaživanje, silikagel.

\title{
PRESERVATION OF TECHNICAL SYSTEMS BY AIR DEHUMIDIFICATION
}

Summary:

A contemporary preservation procedure consists of air-tightening equipment and maintaining humidity in an air-tight area below the threshold value of susceptibility to corrosion. Humidity of the atmosphere can be eliminated by static and dynamic procedures.

Key words: preservation, corrosion, relative humidity, tightness, dehumidification, silica gel.

\section{Uvod}

Složeni tehnički sistemi izrađeni su od većeg broja različitih konstrukcionih materijala, koji se različito ponašaju pod dejstvom okoline. Od materijala se zahteva da, s jedne strane, poseduje određene mehaničke osobine, a s druge strane da bude postojan prema uticaju atmosferilija pri normalnim uslovima. Materijali koji zadovoljavaju oba uslova vrlo su skupi, pa se problem rešava tako što se materijalima odgovarajućih mehaničkih karakteristika dodaje naknadna zaštita.

Zaštita tehničkih materijalnih sredstava (TMS) od atmosferske korozije, $u$ periodu kada nisu u eksploataciji, naziva se konzervacija. Ona zauzima značajno mesto u sistemu održavanja TMS, jer ko- rozija spada u faktore visokog rizika sa stanovišta borbene gotovosti.

Cilj konzervacije jeste da spreči propadanje materijala za vreme dok TMS nisu u upotrebi, tj. za vreme skladištenja. Skladištenje TMS vrši se u zatvorenim objektima, pod nastrešnicama i na otvorenom prostoru. Zatvoreni objekti (magacini i hale) ne dozvoljavaju da atmosferske padavine i sunčeva svetlost dođu u dodir sa uskladištenom opremom. Nastrešnice pružaju zaštitu od atmosferskih padavina, ali samo kada je vreme stabilno, pa se pri skladištenju pod nastrešnicama i na otvorenom prostoru koriste zaštitne navlake - cerade.

Propadanje materijala uzrokuje povećana vlažnost, temperatura, zagađenost 
vazduha i sunčeva svetlost [1]. U uslovima povećane vlažnosti vazduha dolazi do:

- korozije tehničkih metala;

- smanjenja otpornosti elektroizolacionog materijala:

- stvaranja plesni na tekstilu i koži;

- bubrenja higroskopnih materijala (drvo i tekstil);

- omekšavanja kartonskog pakovanja.

\section{Odvlaživanje kao postupak zaštite}

Zaštita uskladištene opreme od korozije može se izvršiti na nekoliko načina, od kojih neki više, a drugi manje ostvaruju osnovne zahteve konzervacije, a to su: tehnički (što znači zaštita od korozije) i taktički (što znači imati opremu raspoloživu za momentalnu upotrebu).

Klasični postupak zaštite kontaktnom metodom, sastoji se u nanošenju zaštitnih sredstava (zaštitnih ulja, masti i termoplastičnih masa) na površine koje se štite čime je prvi uslov uglavnom zadovoljen. Drugi uslov, uglavnom, nije ispunjen i zavisi od specifičnosti zaštitnih sredstava. U određenim situacijama zaštita može biti neprimerena ako je vreme dekonzervacije i dovođenje opreme $u$ stanje borbene gotovosti duže od zahtevanog vremena kada je oprema morala biti upotrebljena.

Ova dva kontradiktorna zahteva konzervacije mogu se uskladiti ako se u postupku zaštite od atmosferske korozije ne tretira metal već lokalna atmosfera. To se postiže metodom hermetizacije koji se sastoji u izolovanju pojedinih delova, sklopova i kompletnih TMS i u obradi korozione sredine unutar izolovanog prostora. Hermetičnost se može postići metalnom i plastičnom ambalažom, navlakama od metalnih i plastičnih folija i adaptacijom građevinskog objekta.

Pri korišćenju metalne i plastične ambalaže (kontejnera), hermetičnost se postiže postavljanjem termoplastičnog gita ili samolepljive trake na spoju između sanduka i poklopca sanduka. Radi izrade navlaka folija se reže u komade odgovarajuće veličine, a zatim se aparatom za zavarivanje formira navlaka.

Hermetizacijom se agresivna sredina ograničava na prostor koji se nalazi između sredstva i omotača kojim je izvršena hermetizacija. U tom prostoru nalaze se određene količine kiseonika, vodene pare i drugih agensa korozije koji mogu uzrokovati degradaciju karakteristika tehničkih materijala.

Količina vodene pare $u$ hermetičnom pakovanju zavisi od uslova u kojima je izvršena hermetizacija i poroznosti omotača. Radi smanjenja količine zarobljene vlage unutar omotača, hermetizacija se vrši na sobnoj temperaturi i relativnoj vlažnosti do $60 \%$. Ukoliko su ove vrednosti veće na nižim temperaturama će doći do kondenzacije veće količine vodene pare. Na primer, ako se hermetizacija vrši u uslovima relativne vlažnosti od $60 \%$ i temperature od $27^{\circ} \mathrm{C}$ onda se u $1 \mathrm{~m}^{3}$ prostora nalazi $15 \mathrm{~g}$ vodene pare (tačka A, slika 1). Kada se takvo pakovanje za vreme skladištenja nađe na temperaturi manjoj od $20^{\circ} \mathrm{C}$ doći će do kondenzacije vodene pare na površini omotača i TMS (tačka B, slika 1). Ukoliko se temperatura u omotaču smanji na $12^{\circ} \mathrm{C}$ doći će do kondenzacije $5 \mathrm{~g}$ vodene pare (tačka C, slika 1).

Hermetičnost nije dovoljna da dugoročno zaštiti TMS, jer se u omotaču zadr- 


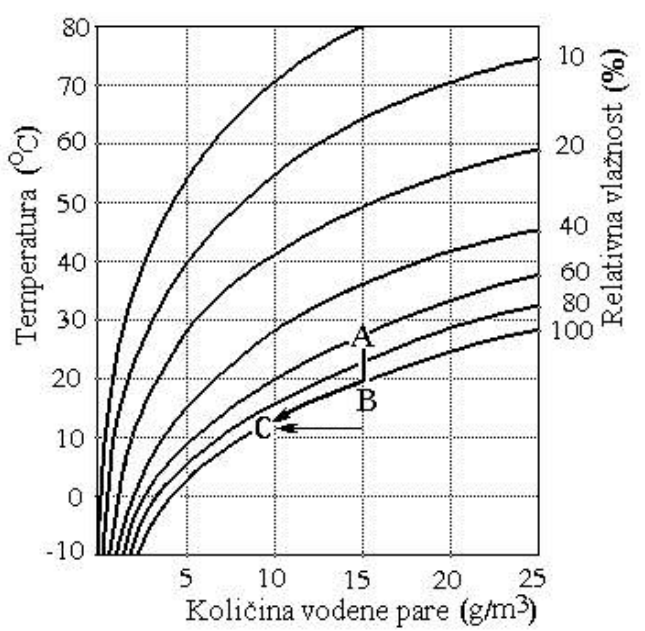

Sl. 1 - Zavisnost količine vodene pare od temperature i relativne vlažnosti

žavaju ili u njega naknadno prodiru agensi korozije. Prodiranje agensâ korozije nastaje zbog poroznosti nekih materijala od kojih su izrađeni omotači. Zato se pri zaštiti opreme na duži period vrši obrada korozione sredine hermetičnog pakovanja, hermetičnog prostora ili prostorije.

Ispitivanja su pokazala, a praksa potvrdila, da se korozija gvožđa ne odvija u suvoj atmosferi tj. u uslovima kada je relativna vlažnost manja od 30\%. Korozija se sporo odvija i u uslovima kada je relativna vlažnost manja od $60 \%[1,2]$. Šematski prikaz zavisnosti korozije gvožđa od vlažnosti vazduha i mogućnosti zaštite opreme prikazana je na slici 2.

Suva atmosfera može se ostvariti statičkim i dinamičkim odvlaživanjem.

\section{Statičko odvlaživanje}

Statičko odvlaživanje primenjuje se za dugoročnu konzervaciju sredstava veze, optičkih instrumenata, raketa, radarskih sistema, oklopnih motornih i drugih vozila koja se mogu hermetizovati, rezervnih sklopova, streljačkog naoružanja, itd.

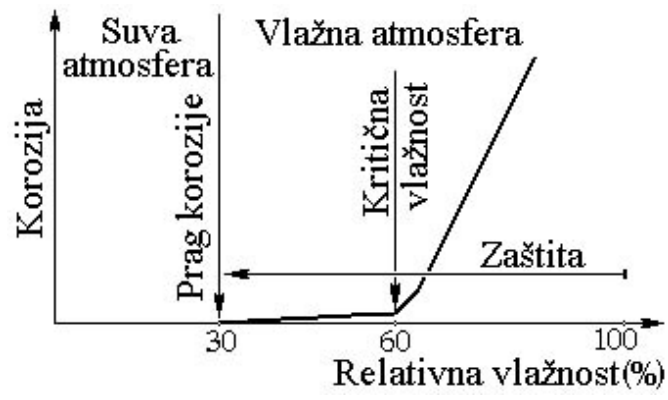

Sl. 2 - Uticaj relativne vlažnosti vazduha na koroziju gvožda i mogućnost zaštite od atmosferske korozije

Konzervacija se provodi čvrstim adsorberima vlage, tzv. odvlaživačima. Oni upijaju vlagu iz hermetične sredine i na taj način, za unapred određeno vreme, održavaju relativnu vlažnost ispod vrednosti kod koje ne dolazi do korozije.

Najpoznatiji odvlaživač je silikagel. On ima veliku sposobnost adsorpcije vodene pare. Najveću sposobnost upijanja ima u uslovima 100\%-tne vlažnosti (do $63 \%$ u odnosu na masu suvog silikagela) [2]. Upijanjem vlage silikagel može u hermetičnim pakovanjima da obezbedi suvu atmosferu u dužem periodu.

$\mathrm{Za}$ upotrebu silikagel se pakuje u pamučne, platnene ili celulozne vrećice, određenih dimenzija u kojima može da stane od 50,100, 250, 500, $1000 \mathrm{~g}$ ili nekoliko kilograma silikagela.

Vrećice sa silikagelom postavljaju se i pričvršćuju na različita mesta oko tehničkog sredstva koje se štiti, tako da čitav prostor unutar pakovanja bude u suvoj atmosferi (slika 3). Između površine metala i vrećica sa silikagelom postavlja se parafinisani papir ili plastična folija, čime se izbegava pojava korozije usled dodira vlažnog silikagela i metala. 


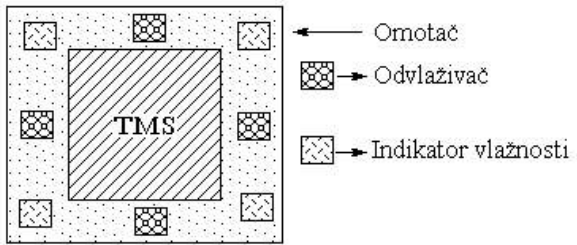

Sl. 3 - Šematski prikaz konzervacije pomoću odvlaživača

Masa silikagela, koja se stavlja u hermetično pakovanje, proračunava se na osnovu propustljivosti vodene pare materijala za hermetizaciju, ukupne zapremine hermetičnog pakovanja, adsorpcione moći silikagela, higroskopnosti i količine materijala za ispunu, veka trajanja konzervacije i uslova čuvanja $[2,3]$.

Stanje vlažnosti unutar hermetičnog pakovanja prati se pomoću indikatora vlažnosti na bazi kobalt-hlorida $\left(\mathrm{CoCl}_{2}\right)$. Ova materija menja boju u zavisnosti od sadržaja vlage i to od izrazito plave - kada je suva, do crvene - kada je vlažna. Prelaz od svetloplave do ružičaste boje odvija se pri relativnoj vlažnosti od $40 \%$.

Kobalthloridom impregnišu se komadi od bele tkanine, veličine $30 \times 50$ $\mathrm{mm}$. Nakon impregnacije i sušenja indikator vlažnosti se do upotrebe čuva u hermetički zatvorenim staklenim, metalnim ili plastičnim posudama. Postavlja se $\mathrm{u}$ hermetično pakovanje na vidljivo mesto koje je udaljeno od mesta sa vrećicama silikagela, a u jedno pakovanje može se postaviti više komada. Njihov broj zavisi od složenosti i veličine tehničkog sredstva koje se zaštićuje.

Zamena indikatora vlažnosti i silikagela vrši se nakon što se pri pregledima konzervisane opreme uoči njegova ružičasta boja. U svakom skladištu TMS konzervisanih metodom hermetizacije postavlja se etalon sa objašnjenjem značenja boje indikatora vlažnosti pri različitim stepenima vlažnosti.
Etalon sa objašnjenjem značenja boje indikatora vlažnosti

\begin{tabular}{|c|c|}
\hline Boja & Relativna vlažnost (\%) \\
\hline Plava & Od 0 do 30 \\
\hline Svetloplava & Od 30 do 40 \\
\hline Ružičasta & Od 40 do 50 \\
\hline Crvena & Od 50 do 100 \\
\hline
\end{tabular}

Zaštita silikagelom traje nekoliko godina i zavisi, prvenstveno, od karakteristika materijala pomoću kojih je izvršena hermetizacija, količine odvlaživača $i$ uslova čuvanja.

Konzervacija metodom hermetizacije uz upotrebu silikagela ima velike prednosti u odnosu na zaštitu zaštitnim uljima, mastima i solventima, i to:

- postupak zaštite je veoma jednostavan. Kada se silikagel zasiti vlagom zamenjuje se suvim, a vlažan šalje na regeneraciju, koja se vrši u električnim pećima;

- silikagel se može primeniti za zaštitu svih materijala. Pored sprečavanja korozije silikagel smanjuje mogućnost nastanka plesni;

- postupak aktiviranja konzervisanog sredstva je jednostavan, a sastoji se od otvaranja hermetičnog pakovanja, uklanjanja materijala kojim je izvršena hermetizacija, i uklanjanja vrećica sa silikagelom i indikatora vlažnosti.

\section{Dinamičko odvlaživanje}

Dinamičko odvlaživanje realizuje se pomoću agregata za odvlaživanje. Izmena vlage obavlja se u lagano rotirajućem adsorpcionom kolu ili rotoru. Rotor je izrađen od mehaničkog nosećeg vatrootpornog materijala koji je impregnisan odgovarajućim odvlaživačem. Sastoji se od mnoštva koaksijalnih kanalića sa glavnom osovinom, tako da ima površinu od preko $3000 \mathrm{~m}^{2} / \mathrm{m}^{3}$. Cevasti oblik saća omogućuje laminarno strujanje vazduha, 
sa minimalnim trenjem i padom pritiska. Vazduh se propušta kroz rotor brzinom od oko $2,5 \mathrm{~m} / \mathrm{s}$.

Rotor se okreće brzinom od 7 obrtaja na sat. Obrtanjem ,prolazi“ kroz sekciju za odvlaživanje usisnog vazduha i kroz sekciju za regeneraciju odvlaživača. U sekciji za odvlaživanje dolazi do adsorpcije vlage, a u sekciji za regeneraciju do oslobađanja vlage iz odvlaživača pomoću toplog vazduha. Nakon regeneracije adsorpciona masa ponovo preuzima vlagu. Oba procesa: adsorpcija vlage i regeneracija odvlaživača odvijaju se istovremeno, čime se ostvaruje kontinuirano odvlaživanje vazduha. $\mathrm{Na}$ taj način $\mathrm{u}$ prostoriji se postiže odgovarajuća mikroklima sa niskom relativnom vlažnošću u kojoj se ne može odvijati elektrohemijska korozija.

Rad agregata može se automatizovati, najčešće higrostatskom metodom. Vrednost vlažnosti koja se želi održavati podešava se na posebnom higrometru, tako da relej automatski uključuje agregat.

Šematski prikaz rada agregata za dinamičko odvlaživanje prikazan je na slici 4, a njegov položaj u skladišnom objektu na slici 5 .

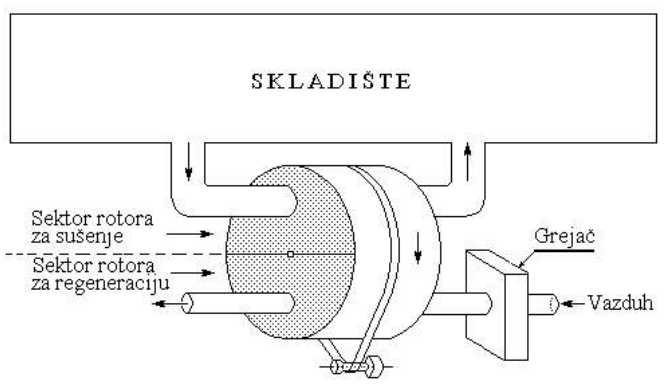

Sl. 4 - Šematski prikaz rada agregata za dinamičko odvlaživanje

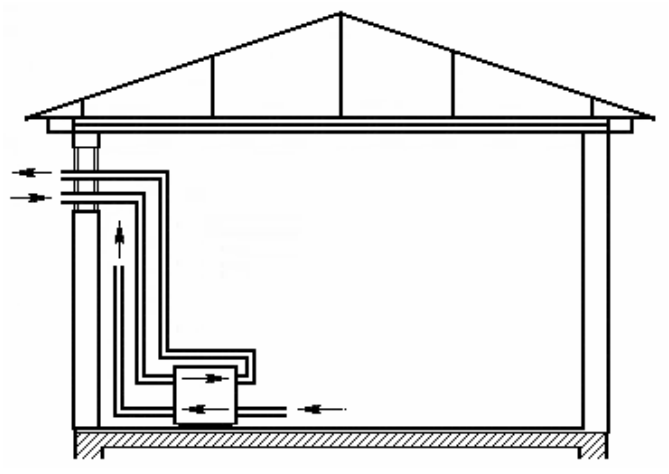

Sl. 5 - Položaj agregata za odvlaživanje u skladišnom objektu

$\mathrm{Na}$ tržištu postoje agregati različitog kapaciteta. U praksi se istovremeno može primeniti nekoliko agregata, čime se omogućuje održavanje relativne vlažnosti u prostoru od nekoliko $\mathrm{m}^{3}$ do nekoliko hiljada $\mathrm{m}^{3}$. U takvim uslovima omogućena je zaštita pojedinih TMS i njihovih sklopova, kao i kompletnog naoružanja i vojne opreme jedne ili više jedinica istovremeno. Upravo zbog toga agregati za odvlaživanje imaju veliku primenu u svetu za zaštitu naoružanja i ostale vojne opreme u stabilnim objektima i na položaju.

Agregati za odvlaživanje mogu se primeniti i za zaštitu naoružanja i vojne opreme na položaju, ukoliko se raspolaže odgovarajućom podlogom i odgovarajućim navlakama (slike 6 i 7). U ovom slučaju nije bitno da se u blizini nalazi izvor električne energije, jer se odvlaživači mogu napajati preko elektro-agregata.

Dinamičko odvlaživanje funkcioniše sigurno i pouzdano uz najmanje energetske i materijalne troškove. Sistem konzervisanja suvim vazduhom obezbeđuje kontrolu vlažnosti vazduha unutar hermetičkog prostora i garantuje sigurnost protiv korozije i drugog štetnog delovanja vlage na uskladišteni materijal. 


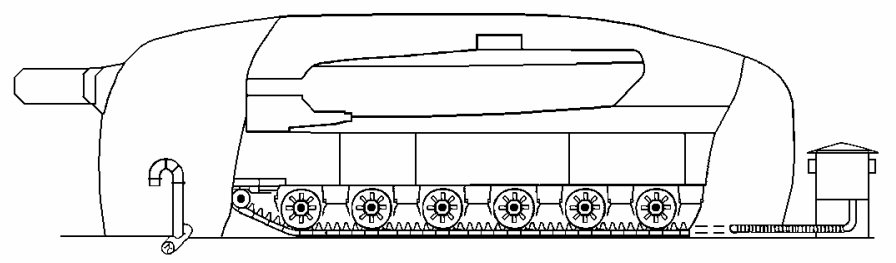

Sl. 6 - Šematski prikaz zaštite dinamičkim odvlaživanjem tenka smeštenog ispod plastične navlake

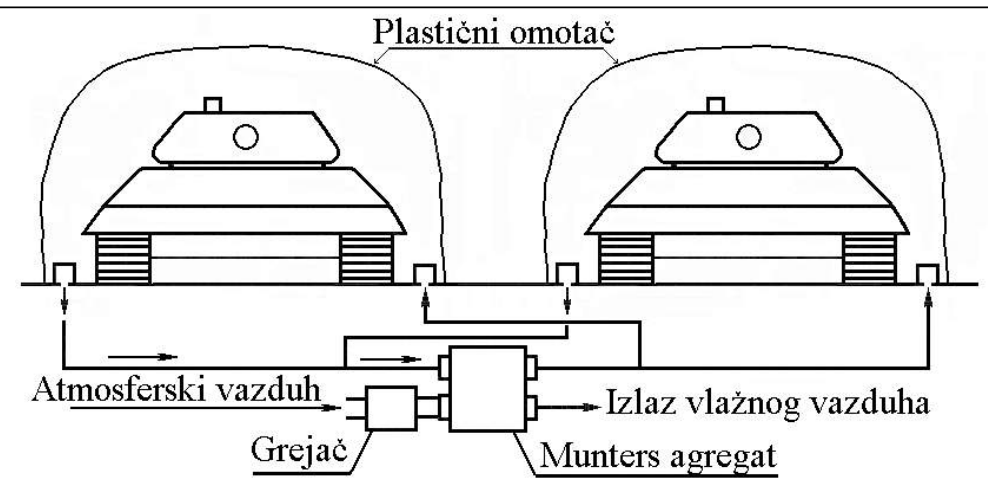

Sl. 7 - Šematski prikaz zaštite dva tenka postupkom dinamičkog odvlaživanja

\section{Zaključak}

Zaštita tehničkih sistema od degradacije za vreme skladištenja može se vršiti postavljanjem opreme u odgovarajuća hermetična pakovanja i hermetične prostore uz održavanje vlažnosti vazduha ispod vrednosti pri kojoj ne dolazi do korozije. To se ostvaruje statičkim i dinamičkim odvlaživanjem.

Statičko odvlaživanje ostvaruje se pomoću silikagela, a primenjuje se za zaštitu opreme koja se čuva u hermetičnim pakovanjima od metalne i plastične ambalaže i omotačima od plastične folije.

Dinamičko odvlaživanje ostvaruje se pomoću agregata za odvlaživanje i primenjuje se za zaštitu velikog broja iste ili različite opreme. Primena ovog postupka konzervacije uslovljena je obezbeđenjem uređaja za odvlaživanje i hermetičnosti prostorije (građevinski obje- kat), odnosno hermetičnosti prostora (nepropustljiva plastična navlaka).

Postupak konzervacije odvlaživanjem je jednostavan i obezbeđuje sigurnu zaštitu TMS u dužem periodu u svim vremenskim uslovima.

Dekonzervacija sredstava konzervisanog statičkim odvlaživanjem je jednostavna, a sastoji se od otvaranja hermetičnog pakovanja, uklanjanja materijala kojim je izvršena hermetizacija, kao i uklanjanja silikagela i indikatora vlažnosti.

Sredstva konzervisana dinamičkim odvlaživanjem čuvaju se u eksploatacionom stanju, tako da se mogu u svakom trenutku upotrebiti.

Literatura:

[1] Vujičić, V.: Korozija i tehnologija zaštite metala, Vojna akademija, Beograd, 2002.

[2] Tehnička uprava SP GŠ VJ: Uputstvo za konzervaciju tehničkih materijalnih sredstava, TU-V, 5102, 1997. 